\title{
INCLUSIVE EDUCATION: A ROADMAP FOR THE QUALITATIVE TRANSFORMATION IN EDUCATION
}

\author{
* Ms. Neetu Guleria \\ Research Scholar, \\ Amity Institute of Education \\ Amity University, Noida \\ Uttar Pradesh, India \\ **Prof. (Dr.) Alka Mudgal \\ Head of Institute, \\ Amity Institute of Education \\ Amity University, Noida \\ Uttar Pradesh, India
}

\begin{abstract}
Inclusive Education (IE) is a revolutionary approach in the system of education to cater to the educational needs of marginalized Children with Special Needs (CWSN). CWSN also aspire \& hope for additional guidance in meeting academic, social \& emotional milestones apart from their medical requirements. By embracing learner centric approach, the distinction of children can be erased right from the beginning of their journey in life as Able bodied \& Children with special needs. This paper aims to highlight project strategies which can give an insight into an effortless introduction of IE curriculum in educational institutions. Early Intervention \& detection modalities discussed in this paper will help in preventing the developmental delays in CWSN. The authors recommend change in the curriculum based on the individual needs of children, regular evaluation of Policies by the Government, integrating Physical education \& shift in the ideology of the stakeholders in educational institutions which will aid in overcoming existing hurdles thereby paving the way towards seamless inclusion of CWSN in mainstream teaching.
\end{abstract}

Keywords: Inclusive Education (IE); Children with Special Needs (CWSN), Early Intervention \& Detection, Action Plan

\section{INTRODUCTION}

1. Overview of Inclusion in Education. A holistic system of education is important in linking educational inclusion towards the broader objective of educational reforms, this also contribute to sustainable development goals. A quality system of inclusion benefits all the learners with no discrimination towards a person or group. It also supports the values of democracy, tolerance and respect for difference.

2. Inclusion in education is a revolutionary approach in the field of education which aims to revise the present system of education so as to address the needs of a broad spectrum of learners by not only enhancing the standard of education through effective teaching learning approaches but also in promoting diagnostic \& remedial instructional techniques to varied learners, embracing learner centred experiential methodologies, developing suitable content \& teaching learning resources. Strengthening the links between all the stake holders (teachers, students, parents \& society) is important for developing inclusive teaching learning environment both within as well as outside the educational institutions. The following aspects in inclusive education needs to be considered ${ }^{[1][2]}$ :-

(a) Transmitting the values of inclusive education into actions: -

(i) Equality to every human life \& providing support for everybody

to create a feeling of belongingness. 
(ii) Reducing marginalization, prejudice, inhibitions to learning and involvement.

(b) Restructuring traditions, policies and practices to react to pluralism in ways in which value everyone equally.

(c) Linking education system to local and global reality.

(d) Learning the reduction of barriers for a few children to profit children more broadly.

(e) Affirming the right of children to an education of the high-quality in their area.

(f) Improving schools for staff and parents/guardians as well as children.

(g) Highlighting the development of educational communities, their values, as well as accomplishments.

(h) Nurturing mutually sustaining relationships between schools and surrounding communities which recognizes that inclusion in education is one aspect of integration into society.

\section{DISCUSSION}

\section{Inclusion of Children with Special Needs}

(CWSN) $^{[3]}$ The term special needs may be a catch-all phrase, which may ask a huge array of diagnoses and/or disabilities. The description "children with special needs" (CWSN) is for children who may have challenges which are more unadorned than the standard child and will possibly last a lifetime. They too have distinct goals and need added guidance and help meeting academic, social, emotional, and sometimes medical milestones. Inclusion in educational institutions is not a mere facility, it needs to be adhered to maintain the sanctity of the goals of Educational Inclusion.

\section{Categories of Disabilities. CWSN may} have been born with a syndrome, terminal illness, profound cognitive impairment, or serious psychiatric problems. These children will need additional support and extra services. CWSN fall under the broad classification as follows: -

(a) Attention Deficit Disorder

(b) Specific Learning disabilities (dyslexia, dyscalculia, dysgraphia),

(c) Autism

(d) Hearing/ Speech Impairment

(e) Visual Impairment

(f) Intellectual Disability like inability to process simple commands.

(g) Developmental delays/ Delayed milestones / progression

(h) Motor disabilities \& difficulties

(i) Inability to engage in simple ageappropriate cognitive function.

5. Action Plan. Inclusive Education (IE) seeks to totally eradicate the distinction between special and regular education and to afford an appropriate education for all students, regardless of their level of infirmity in their schools as well as in the society. It encompasses a comprehensive reformation of our educational system so that all schools would have the responsibility of providing the facilities, resources, and a suitable curriculum for all students irrespective of disability. ${ }^{[4]}$ Some of the broad measures include: -

(a) Checklist for teachers. The teachers in all classes are to be given a checklist of behavioural problems as well as academic issues faced by the student.

(b) Referral to concerned person. Referred cases are to be handled by counsellor or special educator. One on one session to be given to students and therefore the behaviour of the student is be observed and points noted. 
(c) Assessment Test. An assessment test is to be given to students after building an honest rapport with them. The results of the assessment decide which areas the scholars require intervention.

(d) Intervention. Before sending students for Psychometric and Psycho Educational testing, special educators need to take sessions of the scholars. If the condition of scholars improves then they're not sent for further testing. If they still show signs of some specific disability then they should be sent for further testing from school.

(e) Parents/guardians Collaboration. Collaboration with parents is extremely important to enhance the condition of CWSN. The counselling of parents or

guardians of CWSN may be a challenging job but it is essential. The parents are to be counselled to enable them to accept the very fact that their children have some special needs.

(f) Perspective change. In addition to the above steps, teachers are also are required to develop a sensitive attitude towards CWSN and give their best to incorporate them in school. Proper Pre-service \& In-Service training when imparted along with Integrated lesson plans $\&$ activities are to be prepared, extra attention should be given for the students who are lagging behind, observation of students on regular basis, discussing the performance of particular student with the subject teachers.

\section{Project Execution Strategy. A three-} pronged approach for the uptake of the Inclusive Education in the Educational Institutions will be effective when implemented systematically. ${ }^{\text {[5-12] }}$

(a) Phase-1: This phase includes team planning, team building, coordination, execution as follows: -

(i) Core School Level Inclusive $\underline{\text { Team }}$ - This includes the Head of the
Institution/ Principal, Asst Head \& Special Educators along with the willing parents as primary stakeholders.

(ii) Board of Teachers for assessing requirements - A team or 3 to 5

Educators along with the administrator, IT personnel will function as the Board for the procurement of IE specific aids/ teaching material.

(iii) Project Management Group - The mandate of this team will be to monitor the progress of procurement of items.

(iv) Collection of data of children with special needs class wise with the help of Special Educator \& Counsellor.

(v) Identifying the room for Inclusive Education Resource Room.

(vi) Detailed Core Team will prepare the IE Resource room as per the suggested list by the Board of Teachers.

(vii) Plan procurement of IE Resource room items and obtain approvals from the competent authority once funds are allocated to the school.

(vii) Imparting Training to Special Educators and Core Team to use the different items in the IE Resource Room.

(ix) Develop IEP case by case and use the IE resource room.

(x) Continue to identify the requirements for $\mathrm{CWSN}$ and project requirements based on specific disability.

(xi) Lay down parameters/ 
triggers to identify students who may require IE and to estimate the number of students who may require IE, following criteria may be used: -

\section{(aa) Individual}

parameters- Chronic Illness, Intellectual or cognitive, Behavioural or developmental, Depression or anxiety,

Trauma, Low self-esteem.

(ab) Environmental parameters- Death-injury-service conditions, Separation, Lack of continuity, Attachment, Marital discord, Domestic violence, Substance abuse, Mental \& Physical disorder of parents.

(ac) School factorsBullying, Alienation, Bias, Dislike, no support system to cope.

(b) Phase 2: This is the most important phase in which three important activities will be carried out as per succeeding paragraphs.

(i) Infrastructure development. Case file will be initiated for procurement of stores as per list of items required for execution of work.

(ii) Formulation of policy framework modalities and guidelines. For implementation of the IE in the school, specific policy framework on teacher education needs to be laid down that will focus on shifting the mindset of teachers towards children with differential education needs. Services of special teachers should be available to all children of the schools as per provisions in the schemes.

(iii) Training of Teacher/

Educator for IE. Teachers will be identified as per number and type of special students. Training capsules as well as onsite visits will be carried out to empower the teachers which will focus on

following areas: -

(aa) Formulating IEPs based on assessment documents.

(ab) Training to make Synchronous and Asynchronous lesson plans and teaching \& learning modules.

(ac) Training in use of assistive technologies to cover IE curriculum.

(ad) Training in providing least restrictive environment in and outside classroom.

(ae) Training in adapted and alternate methods of assessment.

Training in development of TLM.

(ag) Training in providing holistic development by integrating art, music, dance and sports into adapted curriculum.

(ah) Training in appropriate communication protocols with all stakeholders.

(ai) Training in basic sign language to all teachers.

(aj) Training in providing functional life skills to students.

(c) Phase-3: This will be the final phase in which the resource centre is expected 
to be fully functional. Actions/ activities planned under this phase include: -

(i) Feedback system: A system of continuous feedback from all stake

holders needs to be put in place for course correction/ improvements.

(ii) $\begin{gathered}\text { Reports/ Returns: } \\ \text { Daily, } \\ \text { weekly and monthly reports to be } \\ \text { submitted }\end{gathered}$
Management.

(iii) Introspection:

Regular meetings with all stakeholders to reflect on progress, factor in new developments and advancement in the field of IE.

(iv) Mid-course

Corrections: (as deemed necessary). Based on reports/ returns, feedback \& introspection, necessary changes to be incorporated to ensure quantitative \& qualitative standards are met and maintained.

7. Limitations of IE. Introduction of IE in the mainstream schools is likely to have specific issues which need to be understood and addressed in order to make IE viable. These include: -

(a) Acceptance - acceptance of IE by parents both special child \& child without special needs is the main hurdle in the Inclusive education.

(b) Lack of awareness of IE even in the urban sector \& voicing the same.

(c) Lack of resources in the educational institutions. (d) Lack of viable plan \& execution strategies in institutions.

(e) Shortage of trained professionals for effective inclusion programmes.

(f) Professional/Teacher training institutes fail to impart hands on experience in the Inclusive set up due to very limited schools riveting the policy whole heartedly.

(g) Bureaucratic red tape which may delay implementation of policies.

(h) Delayed detection of CWSN due to unaware parents \& teachers.

(i) Lack of Social acceptance in general.

\section{Early Detection \& Intervention}

Strategies. The term 'Early Intervention refer to broad experiences \& assistance proved to children, parents \& families during prenatal, neonatal, infancy \& early childhood period of development. ${ }^{[13][14]}$ The main objectives of early intervention programs are:-

(a) Early detection of infants/children at risk.

(b) Early detection of developmental delays/ delay in developmental milestones.

(c) Augmentation of normal development.

(d) Acceleration of developmental rate.

(e) Attainment of new behaviour/ skills.

(f) Decreased dependence / Increase in independent functioning.

(g) Early identification and prevention of secondary handicaps.

(h) Curtailing the effects of the handicapping condition. 
(i) Cost effectiveness.

(j) Psychosocial, emotional \& financial support to the families.

9. The introduction of efficient Early Intervention Programme ordered with deliberate timing \& sequence will alter the anticipated course of development. ${ }^{[15]}$ It is planned to suit the stage of the child, level / severity of functioning \& developmental issues. The range of services for early intervention include identification, healthcare, developmental assistance, therapeutic aide, social assistance, cultural service \& economic aid. With the rapid growth during formative years, presumed \& planned intervention provides the intellectual faculties of the slow learner a second chance to reconnect with developmental stages with adequate potential. Hence, early intervention $\&$ detection services can be preventive, therapeutic, supportive, remedial \& curative.

\section{RATIONALE}

10. Early Intervention Services are distinct services with proven results for the infants and toddlers at risk for developmental delays. ${ }^{[15]}$ When intervention with adequate expertise (Parents/ Teachers/ Counselor or an expert in this field) is done in the initial stages of development of the child in the areas of Health \& well-being, cognitive, affective \& Psychomotor domains remediation will be easy with minimalistic time span. The performance of the child in all these domains in comparison with the abilities of the appropriate peer group when delayed, the child's development is considered at stake until he/she receives desired intervention at early stages of childhood.

\section{RECOMMENDATIONS \& CONCLUDING REMARKS}

11. In order to integrate IE in the mainstream education, the authors recommend the broad measures: - (a) Suitable amendment in the Curriculum is required as per the needs of inclusive society.

(b) Changes in teacher training with specific modules to include IE in order to expand the stance of teachers/educators towards inclusion.

(c) Regular evaluation of qualitative educational policies by the government as well as school authorities to facilitate smooth inclusion.

(d) Suitable distribution of funds \& utilization for teacher training in the inclusive setup.

(e) Integrating adequate Physical education/ sports classes under expert training \& guidance, for refining psychomotor skills through well planned \& implementation of Sports Programme in Inclusive classrooms.

(f) Early Intervention Programmes in the Primary \& Pre-primary educational setups for early detection of problems which will enable early initiation of remedial measures.

(g) By providing suitable guidance in the inclusive classroom by the peer group, teachers, parents and quantified involvement of all the stakeholders of the society along with the government proves to be effective in delineating the progress of Inclusive education.

\section{REFERNCES}

1. Booth \& Ainscow (2011) $3^{\text {rd }}$ Edition.

2. Inclusive Education in India- Concept, Need and Challenges. J D Singh, Ph.D. GV (PG) College of Education (CTE), Sangaria335063, Rajasthan.

3. Inclusion of students with disabilities in new times: responding to the challenge D. Konza 

Edith
Cowan
University,
Handicapped, Manovikasnagar, Secunderabad
d.konza@ecu.edu.au.
- 500009.

4. Dunst 1996 Early Intervention in Inclusive Education.

5. Curriculum Diversification, Cognitive Achievement and Economic Performance: Evidence from Colombia and Tanzania George Psacharopoulos June 1987.

6. Obiakor, FE (2007). Multicultural special education: Culturally responsive teaching. Upper Saddle River, NJ: Pearson Merrill/ Prentice Hall. Obiakor, F. E. (2008).

7. The eight-step approach to multicultural learning and teaching (3rd ed.). Dubuque, IA: Kendall/Hunt.

8. Considering the role of curriculum integration towards inclusive education Magda Nikolaraizi and Sophia Mavropoulou Department of Special Education University of Thessaly Argonaphton and Philellinon 38221, Volos, Greece mnikolar@uth.gr

9. Teacher Education for Inclusion Changing paradigms and innovative approaches Edited by Chris Forlin.

10.Action Plan for Inclusive Education of Children and Youth with Disabilities. Available on http://www.education.nic.in

11. National Policy on Education (PoA-1992). New Delhi: Government of India.

12.NCERT (1998). $6^{\text {th }}$ All-India Educational Survey at http://ncert.nic.in.

13. National Curriculum Framework 2005. New Delhi: NCERT. PP.79-89. Pandey, Y (2006). From Special Education to Inclusive Education: an Analysis of Indian Policy.

14. World Year Book of Education 1999. Social inclusion and inclusive education Marsela Robo. UNESCO (2006): Inclusive Education. Available on

http://portal.unesco.org/education/en/ev.phpURI_ID

15. Organization of Early Intervention Services (2008). National Institute for the Mentally 